\title{
A Study on the Changing Trends of Domestic Tourism Consumption Composition of Urban Residents Grouped by Travel Purpose in China
}

\author{
Guo-Ping ZHANG ${ }^{1,2, a}$ and Xiao-Ying LIU ${ }^{1, b,{ }^{*}}$ \\ ${ }^{1}$ Institute of Nationalities Studies in Southwest, Southwest University for \\ Nationalities,Chengdu,China,610041 \\ ${ }^{2}$ Tourism and Urban-Rural Planning Institute, Chengdu University of \\ Technology,Chengdu,China,610059 \\ a707812178@qq.com, 'Ixylxy9881@sina.com \\ ${ }^{*}$ Corresponding author
}

\begin{abstract}
Keywords: changing trends, domestic tourism consumption composition, urban residents, grouped by travel purpose
\end{abstract}

\begin{abstract}
Domestic tourism of urban residents in China can be divided into five groups by travel purpose: sightseeing, visiting relatives $\&$ friends, business, leisure and the others. Then the annual tourism consumption share of every group (i.e. consumption contribution rate) is calculated by processing the sampling survey data during the 1995-2011 period. With the line chart and the fitting model, the paper analyzes the changing trends of the domestic tourism consumption composition of urban residents in China. The conclusions are as follows: In the past decade, the sightseeing's and the leisure's consumption share were on the rise, the sightseeing's was rising much faster than the leisure's; Business' share was on the decline; Both the visiting relatives \& friends' and the others' share were almost unchanged. Finally, the paper forecasts the changing trends of domestic tourism consumption composition of urban residents in China in the future.
\end{abstract}

\section{Introduction}

Since the 1990's, China's domestic tourism total spending grew at an average of 19.6 percent annually. It grew so fast that it was far ahead of inbound tourism and became the main source of China's tourism revenue. Urban residents' travel rate and per-capita spending were far higher than that of rural residents. Their domestic tourism consumption share accounted for an average of 72.8 percen of the total annually. Therefore, the study on the domestic tourism consumption of urban residents is of great significance to grasp laws and trends of the tourism industry development in China. It also contributed to drawing up tourism development plans and making tourism industry policies.

In Chinese academia, the research on domestic tourism consumption of urban residents focuses on the following fields: the effect of domestic tourism consumption on economic growth [1-2], the influence factors of domestic tourism consumption (such as per-capita disposable income, consumer price index, population development, transportation, the annual average interest rate, housing consumption, etc.) [3-7],the changing of domestic tourism consumption structure (from the perspective of eating, accommodation, transportation, traveling, shopping, entertainment) [8], the comparison of domestic tourism consumption characteristics between urban and rural residents [9-11]. Take a comprehensive view of the existing rearch achievements, there is little on domestic tourism consumption composition of urban residents grouped by travel purpose. The change of urban residents' travel purpose eflects the changing trends of the domestic tourism market demand. 
It is also directly related to the tourism products' production and supply. Thus studying the subject will help tourism enterprises to track market changes and adjust the tourism products' structure. The paper will analyze the changing trends of the domestic tourism consumption composition of urban residents in China by processing the sampling survey data during the 1995-2011 period.

\section{Data}

The original data of the paper include the number of tourists who came from cities and per-capita spending in China during the 1995-2011 period (grouped by travel purpose).They are derived from the books of the Sample Survey on Domestic Tourism in China "(1995-2008) and the Sampling Survey Data on Tourism (2009-2012), which were published by China Travel \& Tourism Press.

In the sample surveys on domestic tourism of urban residents in China from 1995 to 2011 , the groups have changed more than three times except sightseeing, visiting relatives \& friends, leisure. In order to ensure the data's consistency and comparability, the paper puts meetings, official meetings, communication and professional access, exchanges on culture, education and science \& technology, traveling on business into the group of business, it also puts health, religious worship into the group of the others. Table 1 shows the data of the number of tourists who came from the urban and per-capita spending in China during the 1995-2011 period (grouped by travel purpose).

Table 1, The Number of Tourists Who Came from cities and Per-capita Spending in China, Sampling Survey of 1995-2011 (grouped by travel purpose)

\begin{tabular}{|c|c|c|c|c|c|c|c|c|c|c|c|c|}
\hline \multirow{2}{*}{ Year } & \multicolumn{2}{|c|}{ Total } & \multicolumn{2}{|c|}{ Sightseeing } & \multicolumn{2}{|c|}{$\begin{array}{l}\text { Wisiting relatives : } \\
\text { friends }\end{array}$} & \multicolumn{2}{|c|}{ Business } & \multicolumn{2}{|c|}{ Leisure } & \multicolumn{2}{|c|}{ The others } \\
\hline & Tourists & $\begin{array}{l}\text { Per-capita } \\
\text { spengding }\end{array}$ & Tourists & $\begin{array}{c}\text { Per-capita } \\
\text { spengding }\end{array}$ & Tourists & $\begin{array}{l}\text { Per-capita } \\
\text { spengding }\end{array}$ & Tourists & $\begin{array}{l}\text { Per-capita } \\
\text { spengding }\end{array}$ & Tourists & $\begin{array}{c}\text { Per-capita } \\
\text { spengding }\end{array}$ & Tourists & $\begin{array}{l}\begin{array}{l}\text { Per-capita } \\
\text { spengding }\end{array} \\
\text { spent }\end{array}$ \\
\hline 1995 & 9377 & 592.08 & 3204 & 481.6 & 2109 & 420.7 & 2159 & 1115.0 & 1050 & 365.6 & 855 & 386.3 \\
\hline 1996 & 8743 & 715.5 & 3220 & 571.7 & 1787 & 557.8 & 1614 & 1462.6 & 1058 & 393.3 & 1064 & 602.7 \\
\hline 1997 & 9217 & 709.6 & 2501 & 763.5 & 3245 & 520.8 & 1286 & 1341.4 & 1198 & 421 & 987 & 720.9 \\
\hline 1998 & 9273 & 697.3 & 3062 & 704.8 & 2527 & 472.1 & 1322 & 1417.5 & 1289 & 448.6 & 1073 & 618.0 \\
\hline 1999 & 8575 & 625.8 & 2301 & 566.3 & 3548 & 512.3 & 1124 & 1249.5 & 1082 & 469.2 & 520 & 640.5 \\
\hline 2000 & 10971 & 724. 1 & 4388 & 729.7 & 2896 & 548.3 & 1248 & 1512.0 & 1848 & 483.4 & 591 & 634.1 \\
\hline 2001 & 11647 & 765.5 & 4578 & 868.3 & 2938 & 575.9 & 1383 & 1391.1 & 2062 & 441.1 & 686 & 605.3 \\
\hline 2002 & 12754 & 801.6 & 5276 & 836.3 & 3211 & 727.4 & 1267 & 1503.3 & 2296 & 479.2 & 704 & 667.7 \\
\hline 2003 & 10229 & 716.9 & 4275 & 725.4 & 2582 & 646.3 & 806 & 1516.5 & 2161 & 477.1 & 405 & 766.1 \\
\hline 2004 & 12602 & 783.8 & 5683 & 847.8 & 2993 & 611.6 & 891 & 1592.0 & 2483 & 533.5 & 552 & 878.8 \\
\hline 2005 & 14449 & 789.7 & 6500 & 858.3 & 3397 & 668.3 & 1073 & 1619.6 & 2681 & 497.3 & 798 & 613.5 \\
\hline 2006 & 16748 & 817 & 7150 & 887.4 & 3935 & 751.6 & 1111 & 1699.5 & 3453 & 543.7 & 1099 & 560.1 \\
\hline 2007 & 18055 & 917.2 & 7733 & 1037.3 & 3974 & 887.8 & 980 & 1863.2 & 3960 & 594.3 & 1408 & 591.0 \\
\hline 2008 & 36623 & 849.4 & 10010 & 1072.7 & 13444 & 703.3 & 1197 & 2350.6 & 9123 & 682.6 & 2849 & 655.9 \\
\hline 2009 & 42946 & 829.9 & 12400 & 1029.2 & 15400 & 662.5 & 1501 & 2355.8 & 10061 & 682.5 & 3584 & 634.7 \\
\hline 2010 & 44627 & 913.1 & 14671 & 1211.2 & 13848 & 691.1 & 1589 & 2272.4 & 11173 & 667.9 & 3346 & 698.0 \\
\hline 2011 & 21985 & 1140.2 & 6486 & 1212.6 & 6354 & 845.5 & 3342 & 2039 & 5210 & 893.3 & 593 & 600.6 \\
\hline
\end{tabular}

Sources: Based on the data of the Sample Survey on Domestic Tourism in China "(1995-2008) and the Sampling Survey Data on Tourism (2009-2012).

According to the data in Table 1, the annual tourism consumption share of every group (i.e. consumption contribution rate) can be calculated. Table 2 shows the data of the annual tourism consumption share of every group. 
Table 2, the Data of the Annual Tourism Consumption Share of Every Group[\%]

\begin{tabular}{lccccc}
\hline Year & Sightseeing & $\begin{array}{c}\text { Visiting } \\
\text { relatives } \\
\text { friends }\end{array}$ & Business & Leisure & The others \\
\hline 1995 & 27.8 & 16.0 & 43.4 & 6.9 & 5.9 \\
1996 & 27.8 & 16.0 & 43.4 & 6.9 & 5.9 \\
1997 & 27.8 & 16.0 & 43.4 & 6.9 & 5.9 \\
1998 & 27.8 & 16.0 & 43.4 & 6.9 & 5.9 \\
1999 & 27.8 & 16.0 & 43.4 & 6.9 & 5.9 \\
2000 & 27.8 & 16.0 & 43.4 & 6.9 & 5.9 \\
2001 & 27.8 & 16.0 & 43.4 & 6.9 & 5.9 \\
2002 & 27.8 & 16.0 & 43.4 & 6.9 & 5.9 \\
2003 & 27.8 & 16.0 & 43.4 & 6.9 & 5.9 \\
2004 & 27.8 & 16.0 & 43.4 & 6.9 & 5.9 \\
2005 & 27.8 & 16.0 & 43.4 & 6.9 & 5.9 \\
2006 & 27.8 & 16.0 & 43.4 & 6.9 & 5.9 \\
2007 & 27.8 & 16.0 & 43.4 & 6.9 & 5.9 \\
2008 & 27.8 & 16.0 & 43.4 & 6.9 & 5.9 \\
2009 & 27.8 & 16.0 & 43.4 & 6.9 & 5.9 \\
2010 & 27.8 & 16.0 & 43.4 & 6.9 & 5.9 \\
2011 & 27.8 & 16.0 & 43.4 & 6.9 & 5.9 \\
\hline
\end{tabular}

\section{Analysis}

Fig. 1 presents the changes of tourism consumption share of every group during the 1995-2011 period. It breaks the changes down into two periods on the whole: (a) 1995-2007, (b) 2008-2011. Because of Wenchuan Earthquake and the Global Financial Tsunami, a great change happened in 2008.After that, however, the share of every group was closing the one in 2007. Because the total sample decreased by more than half, there was also a great change in 2011.So the changing trends of tourism consumption share of every group during the 1995-2007 period maybe reflect the longer trends.

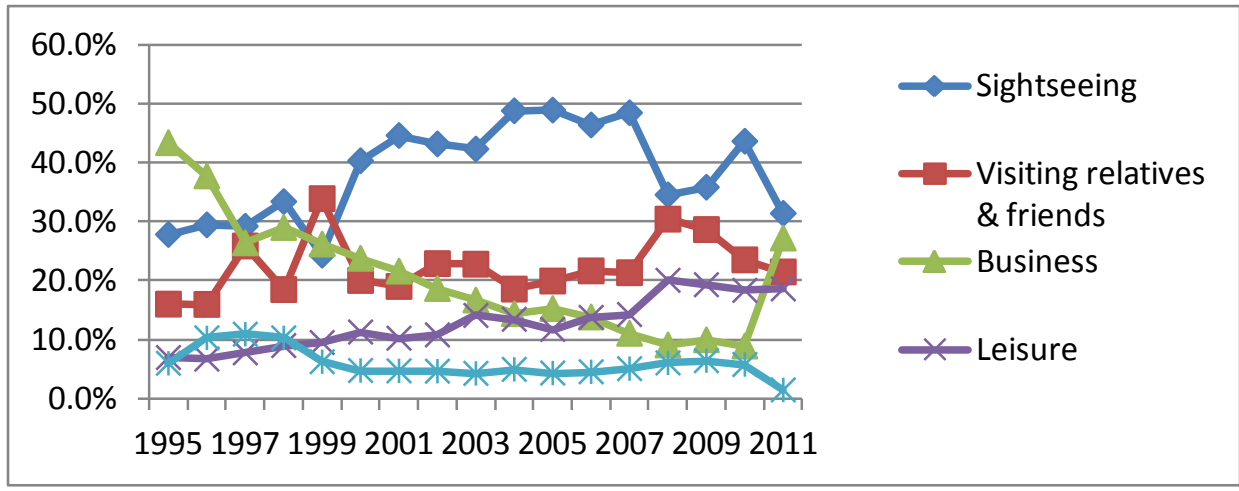

Fig.1 The Change of Tourism Consumption Share of Every Group during the 1995-2011 Period 
In order to know precisely how tourism consumption share of every group changed during the 1995-2007 period, we can build a fitting binary regression model below, using year as the dependent variable, and using the shares as the independent variables.

$$
Y i=\alpha i+b i t+\varepsilon i(t=1,2,3, \ldots ; i=s, v, b, l, o)
$$

In Equation (1), $\mathrm{Yi}$ stands for the share, $\mathrm{t}$ stands for year, both $\alpha \mathrm{i}$ and bi stand for parameters to be estimated, ei stands for a random perturbed variable, i stands for different groups(s stands for sightseeing, v stands for visiting relatives \& friends, b stands for business, 1 stands for leisure, o stands for the others).

According to the results of regression analysis, we build five regression equations as follows:

$$
\begin{aligned}
& Y s=0.247+0.02 t \\
& Y v=0.206+0.001 t \\
& Y b=0.393-0.023 t \\
& Y l=0.062+0.006 t \\
& Y o=0.093-0.004 t
\end{aligned}
$$

From the results of regression analysis, the coefficients of determination $\mathrm{R} 2$ of the five regression equations are 0.794, 0.006, 0.897, 0.879, 0.472. The results show that Equation (2),(4),(5) show higher fitting degree, Equation (6) shows low fitting degree, and Equation (3) shows extremely low fitting degree.They meams Equation (2),(4),(5) have high level of statistical significance, but Equation (3),(6) have low level of statistical significance.

Equation (2) shows that the sightseeing's consumption share was rising at an average 2 percent a year during the 1995-2007 period. Equation (4) shows that the business' was declining at an average 2.3 percent a year. Equation (5) shows that the leisure's was climbing up at an average 0.6 percent a year.Because Equation (3),(6) have low level of statistical significance, the changes of the consumption share of both the visiting relatives $\&$ friends and the others were no clear trend.

\section{Conclusions}

The conclusions are as follows:In the past decade,both the sightseeing's and the leisure's consumption share were on the rise, the sightseeing's was rising faster than the leisure's. The business' consumption share was declining fastly.Both the visiting relatives \& friends' and the others' consumption share were almost unchanged.

\section{Forecasts}

1. The business' consumption share will continue to decline.There are at least two rearons:(1) Economic growth in China has showed downward trend, the budget for business travel from the government and enterprises is hard to increase.(2) Since the Chinese Communist Party held the 18th national congress, the $\mathrm{CCP}$ has started a big campaign against corruption and waste,which will greatly reduce official travels. 
2. The sightseeing's and the leisure's consumption share will continue to rise.There are three main rearons:(1) All the scenic spots in China were always very crowded during Golden Week holidays in the past decade, which shows tourists' demands for sightseeing and leisure were increasing very fastly and there was huge market potential for sightseeing and leisure tourism product.(2) The State Council of China has introduced the Outline for National Tourism and Leisure (2013-2020) in February 2013, which made a very important suggestion to execute the Paid Leave Act in almost the whole country by 2020.Maybe, the outline will promote sightseeing

and leisure tourism.(3) With the country urbanization advancement speeds up uncessingly, a large number of rural workers gradually become citizens who are willing to spend their money on sightseeing and leisure.

3.The fact will be sustainable in the long term that the sightseeing's share accounts for the largest single share of domestic tourism consumption. There is a opinion in academia that the tourism is transforming from sightseeing-type into holiday-spending-type in China.In my view, the transformation does not exist now even in the future. Why? There are three rearons as follows: (1) There are unusually rich resources for seesighting in China but a little resources for leisure relatively.(2) According to the conclusions of the paper, the sightseeing's share was rising much faster than the leisure's in the past decade.(3)The data in Table 1 show that the sightseeing's per-capita spending is 1.5 times as much as the leisure's.So leisure spending is not high level of consumption actually.

4.Both the visiting relatives \& friends' and the others' consumption share will fall at last.In the past decade,the sightseeing's and the leisure's consumption share was rising fast with the business' consumption share fall.But now, the business' share is very poor.So the sightseeing and the leisure will drain the share of the visiting relatives \& friends' and the others'.

5.After years of changing, five groups consumption share may be in a state of dynamic equilibrium.

\section{Acknowledgement}

This research was financially supported by the Subject Construction Fund of Southwest University for Nationalities ( No. 2013XWD-S1202)

\section{References}

[1] Zhang Lifeng,An empirical analysis on the influence of urban residents tourism consumption on economic growth in China,Consumer Economics. 24 (2008) 71-74.

[2] Yang Jianchun,Liu Xiaoying, An analysis on the dynamic relationship between urban residents tourism consumption and economic growth in China,Journal of Southwest University for Nationalities(Humanities and Social Science), 6(2010)209-212.

[3] Zhou Wenli,Li Shiping,An empirical study on the relationship between tourism consumption and income based on Keynes'consumptive function theory, Tourism Tribune,25 (2010) 33-38.

[4] Weng Gangmin,Xu Xiaona,Shang Xuemei, An analysis on influence factors of Urban residents domestic tourism demand in China,Urban Issues,4 (2007) 31-35.

[5] Ren Xue,A study on influence factors of urban tourism per capita consumption in China, Science \& Technology Information, 17 (2009) 100-102 \& 139. 
[6] Ji Wenting, An empirical analysis on the urban residents' tourism consumption in China, Business Economy,11 (2008) 106-107 \& 110.

[7] Liu Wenbin,An analysis on the relationship between urban and rural residents' housing consumption and the tourism consumption in China,China Business \& Trade,10(2010) 225-226.

[8] Li Yiwei,Xia Lingen, An analysis of tourism consuming structure of China's urban residents, Tourism Science, 18 (2004) 30-32 \& 38.

[9] Zhou Wenli,The statistical analysis on urban and rural residents' domestic tourism consumption characteristic, Tourism Forum,8 (2011) 35-42.

[10] Zhou Wenli,Li Shiping,An empirical analysis on consumption structure of urban and rural residents' domestic tours:based on ELES theory, Tourism Science,24 ( 2010) 29-38.

[11] Liu Jiwen,Feng Xuegang,An Empirical Study on the Relationship between Income Gap and Average Propensity to Tourism Consumption in China,Journal of East China University of Science and Technology(Social Science Edition) ,6(2010) 57-66. 